Review

\title{
Functional roles of fish collagen peptides on bone regeneration
}

\author{
Shizuka YAMADA, Kohei YAMAMOTO, Ayako NAKAZONO, Takashi MATSUURA and Atsutoshi YOSHIMURA \\ Department of Periodontology and Endodontology, Nagasaki University Graduate School of Biomedical Sciences, Sakamoto 1-7-1, Nagasaki \\ 852-8588, Japan \\ Corresponding author, Shizuka YAMADA; E-mail: shiduka@nagasaki-u.ac.jp
}

\begin{abstract}
Fish collagen peptides (FCP) derived from the skin, bones and scales are commercially used as a functional food or dietary supplement for hypertension and diabetes. However, there is limited evidence on the effects of FCP on the osteoblast function in contrast to evidence of the effects on wound healing, diabetes and bone regeneration, which have been obtained from animal studies. In this narrative review, we expound on the availability of FCP by basic research using osteoblasts. Low-concentration FCP upregulates the expression of osteoblast proliferation, differentiation and collagen modifying enzyme-related genes. Furthermore, it could accelerate matrix mineralization. FCP may have potential utility as a biomaterial to improve collagen quality and promote mineralization through the mitogen-activated protein kinase and Smad cascades. However, there are few clinical studies on bone regeneration in human subjects. It is desirable to be applied clinically through clinical study as soon as possible, based on the results from basic research.
\end{abstract}

Keywords: Fish collagen peptide, Osteoblast differentiation, Bone regenerative medicine

\section{INTRODUCTION}

Collagen is a major component related to extracellular matrix proteins in multicellular animals including humans, and plays an important role in maintaining a cytoskeleton. Furthermore, it has been widely used as a biomaterial (e.g., as a scaffold for cell and tissue regeneration-related proteins, wound dressing, or dietary supplement) ${ }^{1-17)}$ because of its biocompatibility. In particular, collagen peptides, which are enzymatically hydrolyzed from gelatin, are often administered orally because they are easily digestible ${ }^{18)}$, and have been reported to have a positive effect on skin, cartilage and bone ${ }^{19-32)}$.

Tanaka et al. reported that the oral administration of fish scale collagen peptides to hairless mice inhibited Ultraviolet Light B (UV-B)-induced skin dehydration, reduced epidermal hyperplasia, and decreased soluble type I collagen ${ }^{25}$. In addition, Cod skin-derived collagen peptides have been shown to inhibit photoaging by suppressing the expression of matrix metalloproteinases 1, 3, 9 via the mitogen-activated protein kinase (MAPK) pathway ${ }^{33}$. In other words, collagen peptides have a role in protecting against skin aging. In addition, clinical trials have shown that a 6 -week intake of fish collagen peptides (FCP) improved skin hydration in female volunteers ${ }^{34,35)}$. Kalil et al. reported in their clinical study that there were no side effects or systemic effects by FCP, and that the FCP-treated group showed not only better skin texture and hydration, but also improved brightness ${ }^{36}$. Collagen peptides derived from marine sponge have been shown to exhibit significant antioxidant activity, and to protect cells from UV-induced apoptosis in mouse fibroblasts and human keratinocytes ${ }^{377}$. Thus, they have potential applications in the repair of damaged or photoaged skin $^{37}$. Zang et al. reported that oral administration of collagen peptides derived from Chum salmon skin promoted cutaneous wound healing and angiogenesis through upregulation of vascular endothelial growth factor (VEGF) and fibroblast growth factor (FGF)-2 expression in rats, demonstrating the potential role of FCP as a healing material ${ }^{38}$. Furthermore, the administration of collagen peptides from Chum salmon has also been reported to have a protective effect against early alcoholic liver injury by interfering with increased levels of total cholesterol and triacylglycerol ${ }^{16)}$ and to have an accelerated healing effect on gastric ulcers ${ }^{15}$. Thus, it has been shown to be effective for wound healing of mucous membranes as well as skin. The liver is composed of hepatic lobules, which are lobular veins, interlobular arteries, and interlobular bile ducts, separated from the liver lobules by a connective tissue, Glisson's sheath. When inflammation, such as hepatitis, develops, Glisson's sheath is infiltrated by inflammatory cells and blood glutamyltranspeptidase (GTP) is known to increase ${ }^{39}$. When collagen peptides are ingested, blood peptides, such as proline-hydroxyproline (Pro-Hyp) and hydroxyproline-glycine (Hyp-Gly) inhibit the cellular inflammation induced by tumor necrosis factor (TNF)- $\alpha$; it was thought that this process reduced the inflammation in a collagen peptide-treated group ${ }^{40}$. Several other studies have reported that collagen peptides are also effective in diabetes and hypertension ${ }^{41-43)}$. Hatanaka et al. reported that the glycine-proline-hydroxyproline (Gly-Pro-Hyp) tripeptide is an enzyme that inactivates the hormone that lowers blood glucose levels. It has been reported that it inhibits dipeptidylpeptidase-IV activity $^{43}$. In a rat model of type 2 diabetes, collagen

Color figures can be viewed in the online issue, which is available at J-STAGE.

Received Dec 14, 2020: Accepted May 26, 2021

doi:10.4012/dmj.2020-446 JOI JST.JSTAGE/dmj/2020-446 
peptides derived from the skin of Chum salmon were reported to protect carotid artery vascular endothelial cells by lowering blood glucose levels, and were found to decrease the expression of inflammatory cytokines and adipocytokines in the liver ${ }^{44,45)}$. In addition, treatment with FCP has been shown to improve glucose and lipid metabolic profiles, insulin sensitivity, renal function, and hypertension management in patients with type 2 diabetes and hypertension, suggesting that FCP may have potential utility in patients with both type 2 diabetes and hypertension ${ }^{41)}$. Moreover, it has reported that FCP stabilizes blood glucose levels, reduces the risk of obesity, and promotes prolonged satiety in the clinical study by patients with type 2 diabetes ${ }^{46)}$. Study using mouse 3T3-L1 preadipocytes has shown that it inhibits adipocyte differentiation through a mechanism involving transcriptional repression of main adipogenic regulators, thereby suppressing weight gain and adipogenesis ${ }^{47)}$. Angiotensin-converting enzyme (ACE) inhibitors (e.g., ramipril) are known to have not only a renoprotective effect but to also reduce blood pressure, as they reduce intraglomerular pressure by the dilation of the renal tubules ${ }^{48}$. Collagen peptides have been shown to have ACE inhibitory activity ${ }^{49)}$ and may therefore contribute to the suppression of elevated blood pressure. Articular cartilage damage is one of the most common musculoskeletal disorders we encounter, and affects our quality of life. It has been suggested that collagen peptides extracted from the skin of deep-sea fish such as cod, haddock, and pollock may promote chondrogenic differentiation of primary adipose-derived stromal cells ${ }^{50)}$. It was also reported that oral administration of FCP and glucosamine suppressed cartilage degradation in rabbits with osteoarthritis ${ }^{51)}$. In line with these findings, FCP was shown to promote the chondrogenic differentiation of human mesenchymal stem cells ${ }^{52)}$. In clinical studies, FCP has been proven to promote the synthesis of cartilage matrix and reduce pain in patients with osteoarthritis, making it a promising candidate for the treatment of human osteoarthritis ${ }^{46,53-55)}$. Collagen peptides are thus cryptic peptides with a variety of bioactivities ${ }^{56)}$; however, the detailed mechanisms underlying their effects in these diseases are unclear.

Unlike the organs associated with the abovementioned diseases, bones and teeth are hard tissues composed of inorganic substances (e.g., calcium, magnesium, and phosphorus), organic substances (e.g., type I collagen), and non-collagenous proteins (e.g., osteocalcin and osteonectin) ${ }^{57-63)}$. Based on its structural style, it is often compared to a reinforced concrete building. The reinforcing steel corresponds to collagen, while concrete corresponds to inorganic substances, such as calcium and phosphorus. Collagen provides not only the framework for bones, but also a source of bone flexibility. Osteoporosis has been known to be mainly caused by a decrease in bone density. However, in recent years, it has become clear that bone quality also plays a significant role in osteoporosis ${ }^{64-67)}$. Collagen is the critical factor for bone quality. At the National Institutes of Health (NIH) Consensus Conference in
2000, the definition of osteoporosis was revised from the conventional approach, to the following definition, which focuses on bone mineral density: "a skeletal disorder characterized by compromised bone strength predisposing to an increased risk of fracture". In brief, both bone density and bone quality are involved in bone strength. Thus, the osteogenic effect of collagen peptides needs to be evaluated from the viewpoints of both mineralization-related markers and collagen, which serves as a three-dimensional template for mineralization.

In this paper, we review the effects of FCP on bone regeneration in terms of "characterization of collagen peptides" and "mineralization-related markers and collagen quantity and quality" and provide a perspective on the role of FCP in the field of bone regeneration.

\section{EFFECT OF MOLECULAR WEIGHT OF COLLAGEN PEPTIDES ON OSTEOGENESIS}

Several studies have explored the molecular weight of bioactive collagen peptides ${ }^{68,69)}$. It has been reported that rats treated with orally administered collagen peptides with a molecular weight of less than $2 \mathrm{kDa}$ derived from squid skin showed excellent anti-ACE activity ${ }^{68)}$. In addition, Kim et al. found that collagen peptides with molecular weights of 1.5-4.5 kDa derived from Alaska cod skin showed excellent antioxidant activity and could be used as natural antioxidants by in vitro systems ${ }^{69)}$.

Shimizu et al. used Caco-2 cells to investigate intestinal permeability to molecular weight sizeclassified $\mathrm{FCP}^{70)}$. They revealed that the smallest sized FCP crossed the Caco-2 monolayer most efficiently and that permeability was dependent on peptide size. However, because orally ingested functional peptides may be subjected to digestive degradation in the intestinal tract and/or deactivated by chemical changes, and because some physiological functional components may not have an efficient absorption and uptake mechanism in the intestinal tract, it is difficult to determine whether the effects found by in vitro systems using cultured cell responses will necessarily be effected by oral ingestion. On the other hand, few clinical studies have reported the optimal molecular weight range for patients with osteoporosis or arthritis, and there have been no detailed basic research-based reports on the mechanism. Liu et al. reported that 1,370 and 7,747 Da of bovine bone-derived collagen peptides promoted the expression of alkaline phosphatase (ALP) in MC3T3E1 cells, while 878 Da of collagen peptides had the opposite effect ${ }^{71}$. This result indicates that the effect of ALP is related to the molecular weight distribution of collagen peptides. In a previous study, we examined the expression of mineralization-related markers in NOS-1 cells, which is a human osteosarcoma-derived osteoblast, using FCP of $\sim 2 \mathrm{kDa}$ to $\sim 8 \mathrm{kDa}$ in molecular weight, and found that the ALP activity on day 3 of culture and the protein expressions of osteocalcin (OC), osteopontin (OP) and integrin (ITG) were significantly upregulated in an FCP-supplemented group on day 7 of 
culture $^{72)}$. Furthermore, the gene expressions of the type I collagen $\alpha 2$ chain, lysyl hydroxylase (LH) 1, 2, 3 and lysyl oxidase-like (LOXL) 2, 3, 4 and glycosyltransferase 25 domain 1 (GLT25D1), which are collagen crosslinking-related enzymes, were enhanced on day 3 of MC3T3-E1 cell culture ${ }^{73)}$. FCP also increased collagen synthesis by approximately $15 \%$ on day 14 of culture. In addition, the expression of hydroxylysine (Hyl), which is the source of collagen cross-linking, was increased by $25 \%$. They resulted in an approximately $77 \%$ increase in the formation of pyridinoline (Pyr), a mature crosslink that exists predominantly in bone ${ }^{73)}$. Then, alizarin red S staining on day 21 of culture revealed significantly more minerals in the FCP-supplemented group in comparison to the control group ${ }^{73)}$. The FCP powder was further classified into three fractions of approximately $2,2.5$ and $3 \mathrm{kDa}$ by molecular sieve chromatography on the basis of the chromatogram analyzed by highperformance liquid chromatography. When MC3T3-E1 cells were treated with fractionated FCP for 3 days, they proved a significant enhancement of the LH1 gene expression by approximately 17 -fold (in comparison to the control group) in cells treated with $3 \mathrm{kDa}$ of FCP and approximately 13 -fold in in cells treated with $2 \mathrm{kDa}$ of FCP. As for LH2, the gene expression was enhanced by approximately 2 -fold in in cells treated with $2 \mathrm{kDa}$ of FCP, although the difference was not statistically significant. The gene expression of lysyl oxidase (LOX) was approximately 8-fold higher than that of control group at the $2 \mathrm{kDa}$ of FCP-supplemented group.
Alizarin red S staining also confirmed that MC3T3E1 cells cultured in FCP-containing medium with a molecular weight of approximately $2.8 \mathrm{kDa}$ for 21 days showed more minerals than the same cells cultured in the maintenance medium (unpublished data). These results suggest that the physiological cross-linking of collagen formed actively through collagen cross-linkingrelated enzymes (e.g., LH1, 2 and LOX) by $2-3 \mathrm{kDa}$ of FCP might have resulted in the formation of tenacious collagen fibers, and a three-dimensional collagen template suitable for matrix mineralization promoted mineral deposition and growth.

\section{EFFECT OF AMINO ACID SEQUENCES OF COLLAGEN PEPTIDES ON OSTEOGENESIS}

Hydroxyproline, the main component of collagen, is responsible for the stability of collagen along with proline. In general, it accounts for approximately $10 \%$ of the total amino acids in mammalian type I collagen. On the other hand, the hydroxyproline content of fish collagen is approximately half that of mammalian collagen ${ }^{73,74)}$. It makes the triple helix stability of fish collagen less stable in comparison to mammalian collagen ${ }^{75,76)}$. Furthermore, this property leads to a lower denaturation temperature of fish collagen, while leading to better digestion and absorption than mammalian collagen.

How does the amino acid sequence of collagen peptides affect osteogenesis? Table $1^{77-84)}$ lists some reports on the effect of the amino acid sequences of

Table 1 The effect of amino acid sequence on collagen peptide for osteogenesis

\begin{tabular}{|c|c|c|}
\hline Amino acid sequence & Effect on cell differentiation and osteogenesis & Reference No. \\
\hline \multirow{2}{*}{$\begin{array}{l}\text { RGD motifs } \\
\text { (arginine-glycine-aspartic acid) }\end{array}$} & RGD motifs induce focal adhesion through integrin binding. & 77) \\
\hline & RGD motifs initiate $\alpha_{V}$ integrin signaling in osteoblasts. & 78) \\
\hline \multirow{3}{*}{$\begin{array}{l}\text { DGEA peptides } \\
\text { (aspartic acid-glycine-glutamic } \\
\text { acid-alanine) }\end{array}$} & $\begin{array}{l}\text { DGEA peptides cause the expression of osteogenic protein markers, } \\
\text { e.g. collagen type } 1 \text {, osteopontin, alkaline phosphatase, osteocalcin } \\
\text { and dentin matrix acidic phosphoprotein } 1 \text {. }\end{array}$ & 79) \\
\hline & $\begin{array}{l}\text { E7(heptaglutamate)-DGEA-coupled hydroxyapatite enhances the } \\
\text { adhesion and osteoblastic differentiation of mesenchymal stem cells, } \\
\text { and increases new bone formation in rat tibiae. }\end{array}$ & 80) \\
\hline & $\begin{array}{l}\text { DGEA peptides are involved in type } 1 \text { collagen- } \alpha 2 \beta 1 \text { integrin } \\
\text { interaction on bone marrow cells. }\end{array}$ & 81) \\
\hline \multirow{2}{*}{$\begin{array}{l}\text { Pro-Hyp } \\
\text { (proline-hydroxyproline) }\end{array}$} & $\begin{array}{l}\text { During osteoblast differentiation, Pro-Hyp mediates Runx } 2 \text { activity } \\
\text { though directly binding Foxg } 1 \text {, which has been shown to play a role } \\
\text { in the development of the brain and telencephalon, and increases } \\
\text { Runx } 2 \text { expression. }\end{array}$ & 82) \\
\hline & $\begin{array}{l}\text { Pro-Hyp has a positive effect on osteoblastic differentiation through } \\
\text { upregulation of Runx } 2 \text {, osterix, and collagen type } 1 \alpha 1 \text { chain gene } \\
\text { expression. }\end{array}$ & 83) \\
\hline $\begin{array}{l}\text { Lys-Ser-Ala } \\
\text { (lysine-serine-alanine) }\end{array}$ & $\begin{array}{l}\text { Lys-Ser-Ala promotes cell proliferation, alkaline phosphatase } \\
\text { activity, mineral deposition, and expressions of osteoblastic } \\
\text { differentiation-related gene such as alkaline phosphatase, } \\
\text { osteopontin and osteocalcin in MC3T3-E1 cells. }\end{array}$ & 84) \\
\hline
\end{tabular}


collagen peptides on osteogenesis. The RGD motif (arginine-glycine-aspartic acid) is a cell adhesion active sequence common to many cell adhesion proteins and is present in dozens of proteins (e.g., fibronectin, OP and laminin) as well as collagen. Staatz et al. found that $\alpha 2 \beta 1$ ITG bound to a site within an $\alpha 1$ (I)-CB3 fragment in type I collagen $^{77}$. Subsequently, D'Alonzo et al. found that RGD peptide mimetics initiated $\alpha_{\mathrm{v}}$ ITG signal transduction in MC3T3-E1 cells and that OP and $\alpha_{\mathrm{v}}$ ITG diversely regulated the expression of collagenase- 3 and $\mathrm{OC}$ during osteoblast differentiation ${ }^{78}$. The DGEA peptide (aspartic acid-glycine-glutamic acid-alanine) of type I collagen was revealed to induce osteoblast differentiation ${ }^{79)}$ and it was found that when using heptaglutamate (E7), which is the hydroxyapatite (HA)-binding domain, HA coupled with E7-DGEA promoted mesenchymal stem cell adhesion and osteoblast differentiation and increased new bone ${ }^{80)}$. DGEA peptides may not necessarily have a positive effect on osteogenesis, as it has been reported that the addition of DGEA peptides suppresses the expression of the osteoblast phenotype in bone marrow cells by interfering with the interaction between type I collagen and $\alpha 2 \beta 1$ ITG $^{81}$.

Pro-Hyp has been shown to mediate Runx2 activity and increase the Runt-related transcription factor (Runx2) expression by directly binding to Forkhead Box G1 (Foxg1) recombinant protein during osteoblast differentiation ${ }^{82}$. Although Foxg1 appears to interact with Runx 2 in the absence of Pro-Hyp, Pro-Hyp binds directly to Foxg1 protein in the presence of Pro-Hyp, causing a conformational change in Foxg1 protein and splitting the interaction between Foxg1 and Runx2. Thus, it seems to lead to the increased expression of Runx $2^{82}$. Another study also found that Pro-Hyp did not effect MC3T3-E1 cell proliferation or matrix mineralization, but significantly increased the ALP activity and gene expression of Runx2, osterix and type I collagen $\alpha 1$ chains $^{833}$. These results demonstrated that Pro-Hyp promotes osteoblast differentiation. Thus, there are frequent reports on osteoblast differentiation and matrix mineralization of peptides containing the RGD motif, which is an active sequence associated with cell adhesion, the DGEA peptide which interacts with the cell adhesion molecule ITG, as well as Hyp, which is an amino acid specific to collagen. However, lysine-serinealanine (Lys-Ser-Ala) has also been reported to positively influence osteoblast differentiation ${ }^{84)}$. Lys-Ser-Ala, purified by liquid chromatography, had a high affinity for the core interface residues of the bone morphogenetic protein (BMP) receptor and induced phosphorylation of MAPKs, including p38 MAPK, extracellular signalregulated kinase (ERK) and c-Jun N-terminal kinase, as well as Smads. This might have promoted cell proliferation, ALP activity, mineral deposition and the expression of osteoblast differentiation markers in MC3T3-E1 cells.

\section{EFFECTS OF COLLAGEN PEPTIDES ON COLLAGEN QUALITY AND MINERALIZATION}

It has been reported that type I collagen extracted from tilapia (Oreochromis niloticus) scales improves cell viability and adhesion as well as ALP activity, and promotes matrix mineralization by increasing gene expression of bone sialoprotein in rat odontoblastic cells ${ }^{85}$. It was also revealed that FCP promoted the survival of human primary periodontal ligament cells and upregulated the expression of osteogenesis-related proteins through the ERK signaling pathway, indicating that FCP might be a promising bioactive component for alveolar bone regenerative material ${ }^{86)}$.

Osteoblasts synthesize a collagen matrix, which itself regulates the differentiation of precursor cells into mature osteoblasts. LOX and LH, which are involved in the formation of collagen cross-links synthesized by osteoblasts, also actively contribute to mature collagen formation ${ }^{87}$. Therefore, latylogens such as $\beta$-aminopropionitrile ( $\beta \mathrm{APN})$, which suppresses LOX activity, inhibit stable matrix formation. It is reported that the collagen matrix synthesized by MC3T3-E1 cells treated with $\beta A P N$ for 1 week significantly reduced dehydro-dihydroxylysinonorleucine (deH-DHLNL) and Pyr, which are the main cross-links of bone collagen, in comparison to control cultures ${ }^{88}$. In addition, inhibition of the LOX expression by $\beta A P N$ significantly downregulated the OC mRNA expression to approximately $75 \%$, suggesting that $\beta A P N$ treatment not only inhibits the formation of collagen cross-linking, but also affects the activity and expression of osteoblasts ${ }^{88}$. In our study, as mentioned above, FCP treatment significantly increased the formation of Pyr, which is a stable reductive cross-link, along with the amount of collagen synthesis in MC3T3-E1 cells, which had a positive effect on the expression of mineralization-related proteins, such as OC, OP and ITG, resulting in accelerated mineralization ${ }^{72,73)}$. In addition, we have also confirmed that the filling of the FCP into the bone cavity formed in the mandible of rats accelerated osteogenic repair with minimal inflammatory cell infiltration in comparison to a control group that had no filling of $\mathrm{FCP}^{89}$.

The effect of FCP on matrix mineralization in the presence of collagen with suppressed physiological cross-linking formation is shown in Fig. 1. In order to synthesize collagen with suppressed physiological cross-linking formation, MC3T3-E1 cells were treated with minoxidil $(\mathrm{Mx})$, a specific inhibitor of $\mathrm{LH}$. The group cultured in Mx-containing FCP-free medium showed little or no mineral formation on day 21 of culture, whereas a small amount of mineral deposition was observed in the group cultured in Mx- and FCPcontaining medium, with the group cultured on $\mathrm{Mx}$-free FCP-containing medium showing the greatest amount of mineral deposition. These results indicate that $\mathrm{LH}$ positively contributes to mineralization, while FCP may have the ability to improve mineralization in the presence of vulnerable collagen.

Considering our previous studies and other reports, 


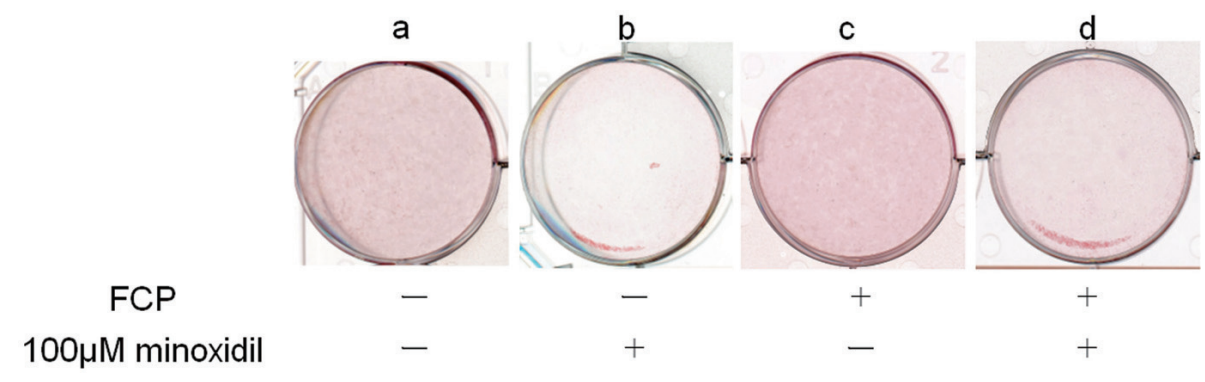

Fig. 1 The effects of minoxidil, which is an inhibitor of lysyl hydroxylase, and FCP on matrix mineralization in MC3T3-E1 cell culture system at 21 days. The cultures were stained with alizarin red $\mathrm{S}$ to visualize mineralized nodules.

(a) The group cultured with $100 \mu \mathrm{M}$ minoxidil $(\mathrm{Mx})$ and $0.2 \%$ FCP-free medium. (b) The group cultured with Mx-containing and FCP-free medium. (c) The group cultured with Mx-free and FCP-containing medium. (d) The group cultured with Mx- and FCP-containing medium.

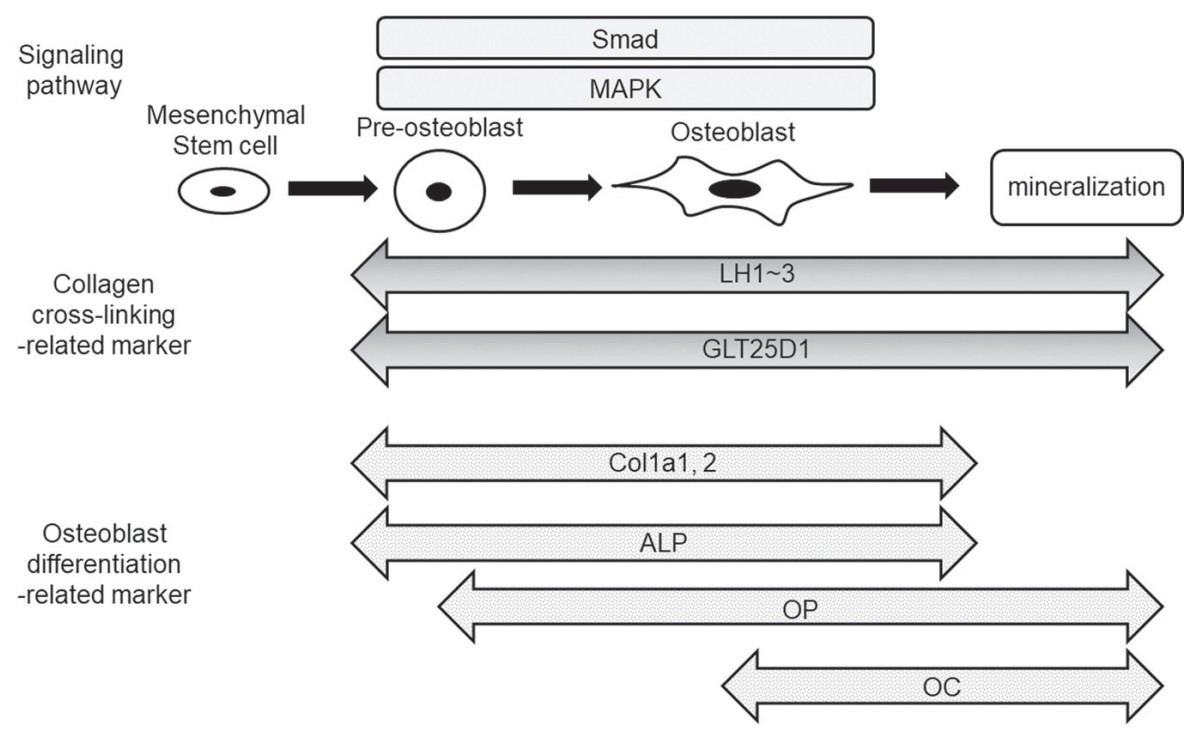

Fig. 2 The osteoblast differentiation and collagen cross-linking-related markers promoted by FCP.

MAPK: mitogen-activated protein kinase, LH: lysyl hydroxylase, GLT25D1: glycosyltransferase 25 domain 1, Col1a1,2: type I collagen $\alpha 1$ chains and 2 chain, ALP: alkaline phosphatase, OP: osteopontin, OC: osteocalcin.

it is presumed that natural functional collagen peptides derived from fish skin, bones and scales may actively induce osteoblast differentiation and improve collagen quality by enhancing the expression of mineralizationrelated markers and collagen cross-linking-related enzyme gene expression through the Smad and ERK/ MAPK cascades, resulting in matrix mineralization (Fig. 2).

On the other hand, as mentioned earlier, our previous studies proved that the gene expressions of LH3 and GLT25D1 in MC3T3-E1 cells were enhanced by $\mathrm{FCP}^{73)}$. It has been reported that LH3 functions mainly as a glucosyltransferase, while GLT25D1 does as a galactosyltransferase for type I collagen in osteoblast culture systems ${ }^{90)}$. It has also been suggested that when
LH3-mediated glucosylation occurs at a specific molecular site, e.g. residue 87 , it is involved in the formed collagen fiber's diameter and the maturation of cross-linking ${ }^{91}$. Further studies are required to determine whether the degree of collagen glycosylation in the FCP-treated group is actually increased at the protein level, and if so to investigate the relationship between glycosylation and matrix mineralization.

\section{CONCLUSIONS AND FUTURE PROSPECTS}

In the past decade, tremendous progress has been made toward the regeneration of dentin, dental pulp and periodontal tissues including alveolar bone and periodontal ligament in the field of dental tissue 
engineering, giving rise to the new field of regenerative dentistry ${ }^{92-97)}$. FCP promotes matrix mineralization by positive effects on collagen synthesis and quality in osteoblasts. Namely, it means the availability to the regeneration of dentin and alveolar bone, which are composed of organic (collagen) and inorganic (minerals) matters in the field of dentistry. It also has potential as a safe bone regeneration agent that can contribute to human health through the effective use of fish byproducts, which are originally marine waste ${ }^{98,99)}$.

However, few clinical studies on human subjects and animal studies have yet been conducted to evaluate the bone regeneration promoting effects of FCP. In order to properly evaluate the therapeutic effects of FCP in many medical fields including the field of bone regeneration, further comprehensive studies based on the results from basic research are necessary. And clinical application of FCP as soon as possible is desirable in other medical fields as well as the field of dentistry.

\section{REFERENCES}

1) Cao H, Chen MM, Liu Y, Liu YY, Huang YQ, Wang JH, et al. Fish collagen-based scaffold containing PLGA microspheres for controlled growth factor delivery in skin tissue engineering. Colloids Surf B Biointerfaces 2015; 136: 1098-1106.

2) Elango J, Saravanakumar K, Rahman SU, Henrotin Y, Regenstein JM, Wu W, et al. Chitosan-collagen 3D matrix mimics trabecular bone and regulates RANKL-mediated paracrine cues of differentiated osteoblast and mesenchymal stem cells for bone marrow macrophage-derived osteoclastogenesis. Biomolecules 2019; 9: 173.

3) Murphy CM, Duffy GP, Schindeler A, O'brien FJ. Effect of collagen-glycosaminoglycan scaffold pore size on matrix mineralization and cellular behavior in different cell types. J Biomed Mater Res A 2016; 104: 291-304.

4) Hu Z, Yang P, Zhou C, Li S, Hong P. Marine collagen peptides from the skin of nile tilapia (oreochromis niloticus): Characterization and wound healing evaluation. Mar Drugs 2017; 15: 102

5) Ouyang QQ, Hu Z, Lin ZP, Quan WY, Deng YF, Li SD, et $a l$. Chitosan hydrogel in combination with marine peptides from tilapia for burns healing. Int J Biol Macromol 2018; 112: 1191-1198.

6) Xiong XY, Liu Y, Shan LT, Xu YQ, Liang J, Lai YH, et al. Evaluation of collagen mixture on promoting skin wound healing in zebrafish caused by acetic acid administration. Biochem Biophys Res Commun 2018; 505: 516-522.

7) Vigneswari S, Murugaiyah V, Kaur G, Abdul Khalil HPS, Amirul AA. Biomacromolecule immobilization: Grafting of fish-scale collagen peptides onto aminolyzed P(3HB-co-4HB) scaffolds as a potential wound dressing. Biomed Mater 2016; 11: 055009 .

8) Wojtkowiak D, Frydrychowski AF, Hadzik J, Dominiak M. Identification of small peptides of acidic collagen extracts from silver carp skin and their therapeutic relevance. Adv Clin Exp Med 2016; 25: 227-235.

9) Castillo-Briceño P, Bihan D, Nilges M, Hamaia S, Meseguer J, García-Ayala A, et al. A role for specific collagen motifs during wound healing and inflammatory response of fibroblasts in the teleost fish gilthead seabream. Mol Immunol 2011; 48: 826-834.

10) Wang Y, Zhang CL, Zhang Q, Li P. Composite electrospun nanomembranes of fish scale collagen peptides/chitooligosaccharides: Antibacterial properties and potential for wound dressing. Int J Nanomedicine 2011; 6: 667-676.
11) Li DD, Li WJ, Kong SZ, Li SD, Guo JQ, Guo MH, et al. Protective effects of collagen polypeptide from tilapia skin against injuries to the liver and kidneys of mice induced by D-galactose. Biomed Pharmacother 2019; 117: 109204.

12) Mei F, Liu J, Wu J, Duan Z, Chen M, Meng K, et al. Collagen peptides isolated from Salmo salar and Tilapia nilotica skin accelerate wound healing by altering cutaneous microbiome colonization via upregulated NOD2 and BD14. J Agric Food Chem 2020; 68: 1621-1633.

13) Zhou T, Wang N, Xue Y, Ding T, Liu X, Mo X, et al. Electrospun tilapia collagen nanofibers accelerating wound healing via inducing keratinocytes proliferation and differentiation. Colloids Surf B Biointerfaces 2016; 143: 415-422.

14) LeBert DC, Squirrell JM, Rindy J, Broadbridge E, Lui Y, Zakrzewska A, et al. Matrix metalloproteinase 9 modulates collagen matrices and wound repair. Development 2015; 142: 2136-2146.

15) Niu H, Wang Z, Hou H, Zhang Z, Li B. Protective effect of cod (gadus macrocephalus) skin collagen peptides on acetic acid-induced gastric ulcer in rats. J Food Sci 2016; 81: H18071815.

16) Lin B, Zhang F, Yu Y, Jiang Q, Zhang Z, Wang J, et al. Marine collagen peptides protect against early alcoholic liver injury in rats. Br J Nutr 2012; 107: 1160-1166.

17) Shen XR, Chen XL, Xie HX, He Y, Chen W, Luo Q, et al. Beneficial effects of a novel shark-skin collagen dressing for the promotion of seawater immersion wound healing. Mil Med Res 2017; 4: 33.

18) Sontakke SB, Jung JH, Piao Z, Chung HJ. Orally available collagen tripeptide: enzymatic stability, intestinal permeability, and absorption of Gly-Pro-Hyp and Pro-Hyp. J Agric Food Chem 2016; 64: 7127-7133.

19) Liu D, Nikoo M, Boran G, Zhou P, Regenstein JM. Collagen and gelatin. Annu Rev Food Sci Technol 2015; 6: 527-557.

20) Lee HJ, Jang HL, Ahn DK, Kim HJ, Jeon HY, Seo DB, et al. Orally administered collagen peptide protects against UVBinduced skin aging through the absorption of dipeptide forms, Gly-Pro and Pro-Hyp. Biosci Biotechnol Biochem 2019; 83: 1146-1156.

21) Kang MC, Yumnam S, Kim SY. Oral intake of collagen peptide attenuates ultraviolet $\mathrm{B}$ irradiation-induced skin dehydration in vivo by regulating hyaluronic acid synthesis. Int J Mol Sci 2018; 19: 3551.

22) Ito N, Seki S, Ueda F. Effects of composite supplement containing collagen peptide and ornithine on skin conditions and plasma IGF-1 levels -A randomized, double-blind, placebo-controlled trial. Randomized Controlled Trial 2018; 16: 482 .

23) Sanchez A, Blanco M, Correa B, Perez-Martin RI, Sotelo CG. Effect of fish collagen hydrolysates on type I collagen mRNA levels of human dermal fibroblast culture. Mar Drugs 2018; 16: 144 .

24) Czajka A, Kania EM, Genovese L, Corbo A, Merone G, Luci C, et al. Daily oral supplementation with collagen peptides combined with vitamins and other bioactive compounds improves skin elasticity and has a beneficial effect on joint and general wellbeing. Nutr Res 2018; 57: 97-108.

25) Tanaka M, Koyama Y, Nomura Y. Effects of collagen peptide ingestion on UV-B-induced skin damage. Biosci Biotechnol Biochem 2009; 73: 930-932.

26) Zhou T, Sui B, Mo X, Sun J. Multifunctional and biomimetic fish collagen/bioactive glass nanofibers: Fabrication, antibacterial activity and inducing skin regeneration in vitro and in vivo. Int $\mathrm{J}$ Nanomedicine 2017; 12: 3495-3507.

27) Wang L, Wang X, Bai F, Fang Y, Wang J, Gao R. The antiskin-aging effect of oral administration of gelatin from the swim bladder of amur sturgeon (Acipenser schrenckii). Food Funct 2019; 10: 3890-3897.

28) Felician FF, Xia C, Qi WQH. Collagen from marine biological 
sources and medical applications. Chem Biodivers 2018; 15: e1700557.

29) Zhang L, Zhang S, Song H, Li B. Effect of collagen hydrolysates from silver carp skin (Hypophthalmichthys molitrix) on osteoporosis in chronologically aged mice: Increasing bone remodeling. Nutrients 2018; 10: 1434.

30) Hou T, Liu Y, Guo D, Li B, He H. Collagen peptides from crucian skin improve calcium bioavailability and structural characterization by HPLC-ESI-MS/MS. J Agric Food Chem 2017; 65: 8847-8854.

31) Chen J, Qiu X, Hao G, Zhang M, Weng W. Preparation and bioavailability of calcium-chelating peptide complex from tilapia skin hydrolysates. J Sci Food Agric 2017 97: 48984903.

32) Xu Y, Han X, Yong L. Effect of marine collagen peptides on long bone development in growing rats. J Sci Food Agric 2010; 90: 1485-1491.

33) Chen T, Fan HHY, Wang S, Chen Q, Si L, Li B. Protective effect of gelatin peptides from pacific cod skin against photoaging by inhibiting the expression of MMPs via MAPK signaling pathway. J Photochem Photobiol B 2016; 165: 3441.

34) Sibilla S, Godfrey M, Brewer S, Budh-Raja A, Genovese L. An overview of the beneficial effects of hydrolysed collagen as a nutraceutical on skin properties: scientific background and clinical studies. Open Nutraceuticals J 2015; 8: 29-42.

35) Matsumoto H, Ohara H, Ito K, Nakamura $Y$, Takahashi S. Clinical effect of fish type1 collagen hydrolysate on skin properties. ITE Lett 2006; 7: 386-390.

36) Petersen Vitello Kalil CL, Campos V, Cignachi S, Favaro Izidoro J, Prieto Herman Reinehr C, Chaves C. Evaluation of cutaneous rejuvenation associated with the use of orthosilicic acid stabilized by hydrolyzed marine collagen. J Cosmet Dermatol 2018; 17: 814-820.

37) Pozzolini M, Millo E, Oliveri C, Mirata S, Salis A, Damonte G, et al. Elicited ROS scavenging activity, photoprotective, and wound-healing properties of collagen-derived peptides from the marine sponge chondrosia reniformis. Mar Drugs 2018; 16: 465.

38) Zhang Z, Wang J, Ding Y, Dai X, Li Y. Oral administration of marine collagen peptides from Chum Salmon skin enhances cutaneous wound healing and angiogenesis in rats. J Sci Food Agric 2011; 91: 2173-2179.

39) Katou K, Mori K. Autoimmune hepatitis with drug-induced pneumonia due to Sho-saiko-to. Nihon Kokyuki Gakkai Zasshi 1999; 37: 641-646.

40) Kouguchi T, Ito A, Iwai K, Shimizu M, Takahata Y, Suzuki T, et al. Chicken collagen hydrolysate-derived peptides inhibit tumor necrosis factor- $\alpha$-induced inflammatory response in endothelial cells. J Food Sci Technol Res 2012; 18: 667-671.

41) Zhu CF, Li GZ, Peng HB, Zhang F, Chen Y, Yong L. Therapeutic effects of marine collagen peptides on chinese patients with type 2 diabetes mellitus and primary hypertension. Am J Med Sci 2010; 340: 360-366.

42) Kim SK, Ngo DH, Vo TS. Marine fish-derived bioactive peptides as potential antihypertensive agents. Adv Food Nutr Res 2012; 65: 249-260.

43) Hatanaka T, Kawakami K, Uraji M. Inhibitory effect of collagen-derived tripeptides on dipeptidylpeptidase-IV activity. J Enzyme Inhib Med Chem 2014; 29: 823-828.

44) Zhu C, Zhang $\mathrm{W}$, Liu J, Mu B, Zhang F, Lai N, et al. Marine collagen peptides reduce endothelial cell injury in diabetic rats by inhibiting apoptosis and the expression of coupling factor 6 and microparticles. Mol Med Rep 2017; 16: 39473957.

45) Zhu C, Zhang W, Mu B, Zhang F, Lai N, Zhou J, et al. Effects of marine collagen peptides on glucose metabolism and insulin resistance in type 2 diabetic rats. J Food Sci Technol 2017; 54: 2260-2269.
46) Cheung RC, Ng TB, Wong JH. Marine peptides: Bioactivities and applications. Mar Drugs 2015; 13: 4006-4043.

47) Lee EJ, Hur J, Ham SA, Jo Y, Lee S, Choi MJ, et al. Fish collagen peptide inhibits the adipogenic differentiation of preadipocytes and ameliorates obesity in high fat diet-fed mice. Int J Biol Macromol 2017; 104: 281-286.

48) Wright Jr JT, Bakris G, Greene T, Agodoa LY, Appel LJ, Charleston J, et al. Effect of blood pressure lowering and antihypertensive drug class on progression of hypertensive kidney disease: results from the AASK trial. JAMA 2002; 288: 2421-2431.

49) Zhang Y, Olsen K, Grossi A, Otte J. Effect of pretreatment on enzymatic hydrolysis of bovine collagen and formation of ACE-inhibitory peptides. Food Chem 2013; 141: 2343-2354.

50) Raabe O, Reich C, Wenisch S, Hild A, Burg-Roderfeld M, Siebert HC, et al. Hydrolyzed fish collagen induced chondrogenic diVerentiation of equine adipose tissue-derived stromal cells. Histochem Cell Biol 2010; 134: 545-554.

51) Ohnishi A, Osaki T, Matahira Y, Tsuka T, Imagawa T, Okamoto Y, et al. Evaluation of the chondroprotective effects of glucosamine and fish collagen peptide on a rabbit ACLT model using serum biomarkers. J Vet Med Sci 2013; 75: 421429.

52) Hsu H, Uemura T, Yamaguchi I, Ikoma T, Tanaka J. Chondrogenic differentiation of human mesenchymal stem cells on fish scale collagen. J Biosci Bioeng 2016; 122: 219225.

53) Clark KL, Sebastianelli W, Flechsenhar KR. 24-week study on the use of collagen hydrolysate as a dietary supplement in athletes with activity-related joint pain. Curr Med Res Opin 2008; 24: 1485-1496.

54) Bruyère $\mathrm{O}$, Zegels $\mathrm{B}$, Leonori L, Rabenda V, Janssen A, Bourges C, et al. Effect of collagen hydrolysate in articular pain: A 6-month randomized, double-blind, placebo controlled study. Complement Ther Med 2012; 20: 124-130.

55) Zdzieblik D, Oesser S, Gollhofer A, König D. Improvement of activity-related knee joint discomfort following supplementation of specific collagen peptides. Appl Physiol Nutr Metab 2017; 42: 588-595.

56) Banerjee P, Shanthi C. Cryptic peptides from collagen: A critical review. Protein Pept Lett 2016; 23: 664-672.

57) Ravindran S, George A. Multifunctional ECM proteins in bone and teeth. Exp Cell Res 2014; 325: 148-154.

58) Paine ML, White SN, Luo W, Fong H, Sarikaya M, Snead ML. Regulated gene expression dictates enamel structure and tooth function. Matrix Biol 2001; 20: 273-292.

59) Aurrekoetxea M, Garcia-Gallastegui P, Irastorza I, Luzuriaga J, Uribe-Etxebarria V, Unda, F, et al. Dental pulp stem cells as a multifaceted tool for bioengineering and the regeneration of craniomaxillofacial tissues. Front Physiol 2015; 6: 289.

60) Widbiller M, Schmalz G. Endodontic regeneration: hard shell, soft core. Odontology 2021; 109: 303-312.

61) Shah D, Lynd T, Ho D, Chen J, Vines J, Jung HD, et al. Pulp-dentin tissue healing response: A discussion of current biomedical approaches. J Clin Med 2020; 9: 434.

62) Cooper PR, Chicca IJ, Holder MJ, Milward MR. Inflammation and regeneration in the dentin-pulp complex: Net gain or net loss? J Endod 2017; 43: S87-S94.

63) Maeda H. Aging and senescence of dental pulp and hard tissues of the tooth. Front Cell Dev Biol 2020; 8: 605996.

64) Martin RM, Correa PH. Bone quality and osteoporosis therapy. Arq Bras Endocrinol Metabol 2010; 54: 186-199.

65) Ohashi S, Tanaka S. Etiology of osteoporosis — decrease of bone mineral density and deterioration of bone quality-. Clin Calcium 2012; 22: 805-811.

66) Anupama DS, Norohna JA, Acharya KK, Ravishankar, George A. Effect of exercise on bone mineral density and quality of life among postmenopausal women with osteoporosis without fracture: A systematic review. Int J Orthop Trauma Nurs 
2020; 39: 100796.

67) Licata AA. Bone density, bone quality, and FRAX: Changing concepts in osteoporosis management. Am J Obstet Gynecol 2013; 208: 92-96.

68) Lin L, Lv S, Li B. Angiotensin-I-converting enzyme (ACE) -inhibitory and antihypertensive properties of squid skin gelatin hydrolysates. Food Chem 2012; 131: 225-230.

69) Kim SK, Kim YT, Byun HG. Isolation and characterization of antioxidative peptides from gelatin hydrolysate of Alaska Pollack skin. J Agric Food Chem 2001; 49: 1984-1989.

70) Shimizu K, Sato M, Zhang Y, Kouguchi T, Takahata Y, Morimatsu F, et al. Molecular size of collagen peptide reverses the permeability of Caco-2 cells. Biosci Biotechnol Biochem 2010; 74: 1123-1125.

71) Liu J, Si S, Qin Y, Zhang B, Song S, Guo Y. The effect of different molecular weight collagen peptides on MC3T3-E1 cells differentiation. Biomed Mater Eng 2015; 26 Suppl 1: S2041-2047.

72) Yamada S, Yoshizawa Y, Kawakubo A, Ikeda T, Yanagiguchi K, Hayashi Y. Early gene and protein expression associated with osteoblast differentiation in response to fish collagen peptides powder. Dent Mater J 2013; 32: 233-240.

73) Yamada S, Nagaoka H, Terajima M, Tsuda N, Hayashi Y, Yamauchi M. Effects of fish collagen peptides on collagen post-translational modifications and mineralization in an osteoblastic cell culture system. Dent Mater J 2013; 32: 8895.

74) Bae I, Osatomi K, Yoshida A, Osako K, Yamaguchi A, Hara K. Biochemical properties of acid-soluble collagens extracted from the skins of underutilised fishes. Food Chem 2008; 108: 49-54.

75) Eastoe JE. The amino acid composition of fish collagen and gelatin. Biochem J 1957; 65: 363-368.

76) Giraud-Guille MM, Besseau L, Chopin C, Durand P, Herbage D. Structural aspects of fish skin collagen which forms ordered arrays via liquid crystalline states. Biomaterials 2000; 21: 899-906.

77) Staatz WD, Fok KF, Zutter MM, Adams SP, Rodriguez BA, Santoro SA. Identification of a tetrapeptide recognition sequence for the alpha 2 beta 1 integrin in collagen. J Biol Chem 1991; 266: 7363-7367.

78) D’Alonzo RC, Kowalski AJ, Denhardt DT, Nickols GA, Partridge NC. Regulation of collagenase-3 and osteocalcin gene expression by collagen and osteopontin in differentiating MC3T3-E1 cells. J Biol Chem 2002; 277: 24788-24798.

79) Yoo SY, Kobayashi M, Lee PP, Lee SW. Early osteogenic differentiation of mouse preosteoblasts induced by collagenderived DGEA-peptide on nanofibrous phage tissue matrices. Biomacromolecules 2011; 12: 987-996.

80) Culpepper BK, Phipps MC, Bonvallet PP, Bellis SL. Enhancement of peptide coupling to hydroxyapatite and implant osseointegration through collagen mimetic peptide modified with a polyglutamate domain. Biomaterials 2010; 31: 9586-9594.

81) Mizuno M, Fujisawa R, Kuboki Y. Type I collagen-induced osteoblastic differentiation of bone-marrow cells mediated by collagen-alpha2beta1 integrin interaction. J Cell Physiol 2000; 184: 207-213.

82) Nomura K, Kimira Y, Osawa Y, Shimizu J, KataokaMatsushita A, Mano H. Collagen-derived dipeptide prolyl hydroxyproline directly binds to foxg1 to change its conformation and inhibit the interaction with Runx2. Biosci Biotechnol Biochem 2019; 83: 2027-2033.

83) Kimira Y, Ogura K, Taniuchi Y, Kataoka A, Inoue N, Sugihara $\mathrm{F}$, et al. Collagen-derived dipeptide prolyl-hydroxyproline promotes differentiation of MC3T3-E1 osteoblastic cells. Biochem Biophys Res Commun 2014; 453: 498-501.

84) Heo SY, Ko SC, Nam SY, Oh J, Kim YM, Kim JI, et al. Fish bone peptide promotes osteogenic differentiation of MC3T3E1 pre-osteoblasts through upregulation of MAPKs and Smad pathways activated BMP-2 receptor. Cell Biochem Funct 2018; 36: 137-146.

85) Tang J, Saito T. Biocompatibility of novel type I collagen purified from tilapia fish scale: An in vitro comparative study. BioMed Res Int 2015; 2015: 139476.

86) Liu C, Sun J. Hydrolyzed tilapia fish collagen induces osteogenic differentiation of human periodontal ligament cells. Biomed Mater 2015; 10: 065020.

87) Yamauchi M, Shiiba M. Lysine hydroxylation and crosslinking of collagen. Methods Mol Biol 2008; 446: 95-108.

88) Turecek C, Fratzl-Zelman N, Rumpler M, Buchinger B, Spitzer S, Zoehrer R, et al. Collagen cross-linking influences osteoblastic differentiation. Calcif Tissue Int 2008; 82: 392400.

89) Yamada S, Ikeda T, Yamamoto K, Yanagiguchi K, Hayashi Y. The efficiency of fish collagen peptides for bone regeneration. Jpn J Conserv Dent 2016; 59: 425-431.

90) Sricholpech M, Perdivara I, Nagaoka H, Yokoyama M, Tomer KB, Yamauchi M. Lysyl hydroxylase 3 glucosylates galactosylhydroxylysine residues in type I collagen in osteoblast culture. J Biol Chem 2011; 286: 8846-8856.

91) Sricholpech M, Perdivara I, Yokoyama M, Nagaoka H, Terajima M, Tomer KB, et al. Lysyl hydroxylase 3-mediated glucosylation in type I collagen. Molecular loci and biological significance. J Biol Chem 2012; 287: 22998-23009.

92) Chang WJ, Shinichi A, Kamakura S, Huang RY, Chen JW. Bioengineering materials in dental application. BioMed Res Int 2017; 2017: 2135036.

93) Huang GT, Yamaza T, Shea LD, Djouad F, Kuhn NZ, Tuan $\mathrm{RS}$, et al. Stem/progenitor cell-mediated de novo regeneration of dental pulp with newly deposited continuous layer of dentin in an in vivo model. Tissue Eng Part A 2010; 16: 605-615.

94) Yen AH, Yelick PC. Dental tissue regeneration - a minireview. Gerontology 2011; 57: 85-94.

95) Eramo S, Natali A, Pinna R, Milia E. Dental pulp regeneration via cell homing. Int Endod J 2018; 51: 405-419.

96) Chisini LA, Conde MCM, Grazioli G, Martin ASS, Carvalho RV, Sartori LRM, et al. Bone, periodontal and dental pulp regeneration in dentistry: A systematic scoping review. Braz Dent J 2019; 30: 77-95.

97) Zheng C, Chen J, Liu S, Jin Y. Stem cell-based bone and dental regeneration: a view of microenvironmental modulation. Int $J$ Oral Sci 2019; 11: 23.

98) Shavandi A, Hou Y, Carne A, McConnell M, A Bekhit AE-D. Marine waste utilization as a source of functional and health compounds. Adv Food Nutr Res 2019; 87: 187-254.

99) Senevirathne M, Kim SK. Utilization of seafood processing by-products: Medicinal applications. Adv Food Nutr Res 2012; 65: 495-512. 